\title{
EXAMINING EFFECTIVE FACULTY PRACTICE
}

\section{TEACHING CLARITY AND STUDENT ENGAGEMENT}

\author{
Allison BrckaLorenz, Tony Ribera, \\ Jillian Kinzie, Eddie R. Cole \\ Indiana University
}

This study explores the frequency of student exposure to teaching-clarity bebaviors and the extent to which these behaviors relate to student engagement, deep approaches to learning, and students' self-reports of gains in college. Researchers found that students exposed to more clear teaching bebaviors, such as explaining course goals and requirements, had positive relationships with all of these outcomes. There were particularly strong relationships between students' exposure to clear teaching behaviors and their sense of campus support and self-reports of gains.

Improving the quality of learning in undergraduate education is a national imperative. Regional accreditation agencies have placed greater demands on institutions to provide evidence of student learning and effective teaching. Institutions must also demonstrate that this evidence is being used to make improvements in the quality of student learning. At the core of any agenda to improve undergraduate education is an emphasis on effective teaching practices. As colleges and universities shift 
to a learning-centered paradigm, a growing emphasis is being placed on understanding which teaching practices are effective in promoting student learning (Barr \& Tagg, 1995). There are varying ideas on what constitutes effective teaching; however, one that is often referenced when discussing the characteristics of effective teaching is teaching clarity (Feldman, 1989; Hativa, Barak, \& Simhi, 2001; Sherman, Armistead, Fowler, Barksdale, \& Reif, 1987).

Teaching clarity has been defined as "a cluster of teaching behaviors that result in learners' gaining knowledge or understanding of a topic" (Cruickshank \& Kennedy, 1986,p. 43) and as "the ability of the teacher to provide instruction, expositional or otherwise, which helps students come to a clear understanding of material" (Metcalf, 1992, p. 275).

For this study, we draw from Ginsberg's (2007) work by defining teaching clarity as a teaching method where faculty demonstrate a level of transparency in their approach to instruction and goal setting in an effort to help students better understand expectations and comprehend subject matter. This includes activities such as providing examples and summarizing key points of lectures (Chesebro \& McCroskey, 2001; Myers \& Knox, 2001). Unfortunately, little is known about the extent to which students are exposed to specific teaching clarity-behaviors and the relationship to other important elements of an undergraduate education, such as student engagement, deep learning, and selfreported gains.

\section{Literature Review}

Research suggests that student engagement in educationally purposeful activities is a predictor of student learning (Astin, 1993; Kuh, 2003; Kuh, Cruce, Shoup, Kinzie, \& Gonyea, 2008; Pace, 1980; Pascarella \& Terenzini, 1991). Undergraduate students report higher levels of student engagement and learning at colleges and universities where faculty engage in effective educational practices (Umbach \& Wawrzynksi, 2005). This supports the research of Kuh, Nelson, Laird, and Umbach (2004) who concluded, "Almost across the board, students at institutions where faculty emphasize a range of effective educational practices reported making more progress since starting college on various dimensions of student learning and personal development" (p. 28).

Providing an overview of studies on undergraduate education, Pascarella and Terenzini (2005) position teaching clarity as an effective educational practice by highlighting the positive relationship between teaching clarity and student learning and achievement. Students who 
report higher levels of teaching-clarity and organization experiences tend to grow more on a wide variety of student outcomes, including moral reasoning, leadership, openness to diversity and challenge, and positive attitudes toward literacy. Similarly, students who reported lower levels of these experiences are less likely to grow on these outcomes (Wabash National Study of Liberal Arts Education, n.d.).

Based on a comprehensive review of the research, Pascarella (2006) concluded that student perceptions of instructional practice, such as teaching clarity, had moderate correlations with various measures of course learning, including grades and final examination performance. Studies have identified a relationship between teaching clarity and student comprehension of material (for example, Chesebro \& McCroskey, 2001; Myers \& Knox, 2001), greater satisfaction and achievement (Hativa, 1998), and motivation (Ginsberg, 2007). Also, student perceptions of instructor behaviors, such as explanation of course goals and assignments, have been positively associated with general measures of cognitive growth in the first year of college (Pascarella, Edison, Nora, Hagedorn, \& Braxton, 1996). In general, students struggle to comprehend material and express dissatisfaction with courses when the instructor lacks clarity (Hativa, 1998).

Although teaching clarity is generally promoted as an effective teaching practice, we know little about how widely students are exposed to this practice in undergraduate education. In addition, little research has been done to link teaching clarity to other forms of effective educational practice such as student-faculty interaction or active and collaborative learning. This study explores the frequency of student exposure to teachingclarity behaviors and the extent to which these behaviors relate to student engagement, deep learning, and self-reported gains in college. Three research questions guided this study:

1. What teaching-clarity behaviors are students exposed to most and least frequently?

2. What is the relationship between teaching clarity and student engagement?

3. How does teaching clarity relate to deep learning and students' reports of gains in college?

\section{Methodology}

Undergraduate students from a variety of higher education institutions were surveyed using the National Survey of Student Engagement (NSSE). 


\section{Data Source and Sample}

The data for this analysis come from the 2010 administration of the NSSE. NSSE was designed by a team of assessment experts to measure student behaviors and the time and energy students invest in activities linked to learning and personal development (Hayek \& Kuh, 2004; Kuh, 2001a, 2001b). More specifically, NSSE asks students how often they engage in various effective educational practices, as well as

Table IO. I. Student and Institution Characteristics.

$\begin{array}{cc}\text { First-Year } & \text { Seniors (\%) } \\ \text { Students }(\%) & \end{array}$

Student characteristics

Female

Transfer student

Full-time enrollment

91

Fraternity or sorority

member

Student-athlete

Living on campus

First generation

Traditional age

Race or ethnicity

African American/

88

black

Asian/Pacific Islander

7

Caucasian/white

Hispanic/Latino

Other

13

Primary major field

Arts and humanities

11

Biological sciences

Business

Education

Engineering

Physical science

Professional

Social science

Grades

Mostly A's

12

13

Mostly B's

51

Mostly C's

Institution characteristics

Control
Carnegie classification

Public 
their perceptions of their college environment and various gains while in college. The teaching-clarity item set was adapted from the Wabash National Study (www.liberalarts.wabash.edu/study-overview/) and has been tested in the study's research (see Pascarella, Salisbury, \& Blaich, 2009). The sample for the current study consists of 8,102 (41 percent) first-year students and 11,761 (59 percent) senior students from thirtyeight colleges and universities. (For additional information about student demographics and characteristics see Table 10.1.)

\section{Variables}

Several scales and collections of items were examined in this study, as well as various student-level demographics and institution-level characteristics. The teaching-clarity scale (Table 10.2 ) was created using the additional items about teaching clarity that were administered at the end of the NSSE. These items asked students how often their instructors behaved in various ways such as giving clear explanations of assignments or making abstract ideas and theories understandable.

The remaining scales and benchmarks used in this study were created using items from the core NSSE survey. Student engagement was measured with individual engagement items from the core NSSE survey, as well as four of NSSE's benchmarks of effective educational practice: Level of Academic Challenge, Active and Collaborative Learning, StudentFaculty Interaction, and Supportive Campus Environment. These

Table 10.2. Component Items and Reliability Coefficients for the Teaching-Clarity Scale.

In your experience during the current school year, about how often did your instructors do each of the following? (never, sometimes, often, very often)

Gave clear explanations of assignments

Used examples or illustrations to explain difficult points

Reviewed and summarized course material effectively

Made abstract ideas and theories understandable

Gave assignments that helped you learn the course material

Presented course material in an organized way

Came to class well prepared

Used class time effectively

Explained course goals and requirements clearly

Note: Teaching clarity: Cronbach's alpha $=.93$ for first-year

students and .94 for seniors. 
benchmarks, broad measures critical to student learning and development, are intended to provide feedback on institutional performance and investigate actionable solutions for improvement.

Deep learning and students' self-reported gains in college were measured with scales created from the NSSE survey. Deep learning was assessed with the scales Higher Order Learning, Integrative Learning, and Reflective Learning. Deep approaches to learning get at a deep understanding of an issue, not just the surface knowledge, and a reflection on the relationships between pieces of information. Students' self-reports of gains were measured using the scales Gains in Practical Competence, Gains in General Education, and Gains in Personal and Social Development. These scales explore the degree to which students report having made gains in a variety of competency areas as a result of their undergraduate education. (See nsse.iub.edu for the component items and reliability coefficients of the scales and NSSE's benchmarks of effective educational practice used in this study.)

\section{Analysis}

For all research questions, data from first-year and senior students were analyzed separately in order to present distinct results reflective of the first-year and senior experience in college. To answer the first research question, items on frequencies of teaching clarity were examined. Pearson's $r$ correlations were used to answer the second research question in order to relate the teaching-clarity scale with four of NSSE's benchmarks of effective educational practice and individual engagement items.

Evidence for the third research question was gathered using a series of multivariate ordinary least squares regressions to determine the relationship between students' reports of teaching clarity and the measures of deep learning and student-reported gains. With the teaching-clarity scale as an independent variable, each measure of deep learning and studentreported gains was analyzed as a dependent variable with its own model controlling for gender, transfer status, enrollment status, fraternity or sorority membership, athletic participation, race or ethnicity, primary major field, grades, first-generation status, age, institutional control, and institutional Carnegie classification.

\section{Findings}

For both first-year (FY) and senior students (SR), the most frequently (students responded "often" or "very often") observed teaching-clarity behaviors were instructors' coming to class well prepared (FY: 91.1 
percent, SR: 90.8 percent) and instructors' explaining course goals and requirements clearly (FY: 87 percent, SR: 89.2 percent). The least often observed teaching-clarity behaviors were instructors' reviewing and summarizing course material effectively (FY: 80.3 percent, SR: 83.5 percent) and instructors' making abstract ideas and theories understandable (FY: 75.9 percent, SR: 79 percent).

For both first-years and seniors, the teaching-clarity scale had significant $(p<.001)$, positive relationships with NSSE's benchmarks of effective educational practice. For first-year and senior students, the strongest relationship was found between teaching clarity and Supportive Campus Environment (FY: $r=.537$, SR: $r=.553$ ), followed by Academic Challenge (FY: $r=.397$, SR: $r=.364$ ). Although seniors still had small, positive relationships between teaching clarity and Student-Faculty Interaction (SFI) $(r=.287)$ and Active and Collaborative Learning (ACL) $(r=.200)$, these relationships were stronger for first-year students (SFI: $r=.301$, ACL: $r=.276$ ). These findings suggest that teachingclarity behaviors may be particularly important for the development of first-year students' relationships with their faculty and classmates.

Individual items on the NSSE survey also had significant $(p<.001)$, positive relationships with the teaching-clarity scale. For both first-years and seniors, the items with the highest correlations with the teachingclarity scale were about students' ratings of their relationships with faculty members (FY: $r=.478, \mathrm{SR}: r=.515$ ), of their institution's emphasis on providing the support they need to succeed academically (FY: $r=.473$, SR: $r=.517)$, and of their entire educational experience at their institution (FY: $r=.507$, SR: $r=.525$ ). These findings support the idea that teaching clarity contributes to students' relationships with faculty members and contributes to their overall satisfaction with their college experience.

Controlling for a wide variety of student-level characteristics, regressions indicated significant, positive relationships between teaching clarity and all subscales of deep learning and student-reported gains. Because all continuous independent and dependent variables were standardized before being entered in the models, the unstandardized coefficients can be interpreted as effect sizes. The magnitude of these effect sizes is reflected in Table 10.3. All coefficients were statistically significant and ranged between a small to medium relationship $(+)$ to a large relationship $(++++)$. For both first-years and seniors, the teaching-clarity scale had the strongest relationships with student-reported gains in college, specifically between teaching clarity and student-reported Gains in Practical Competence and Gains in General Education. Again for both 


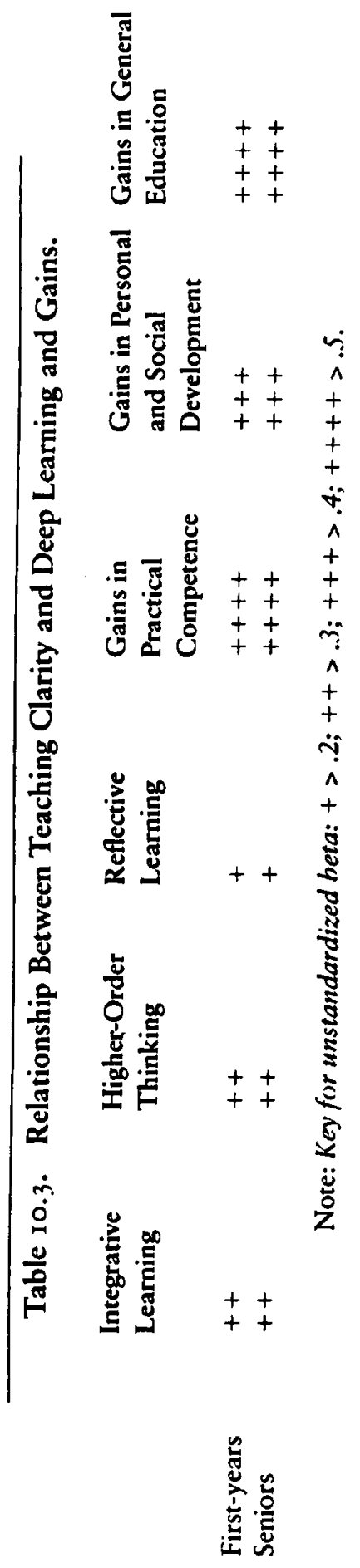


classes, there were slightly stronger relationships between the teachingclarity scale and the Integrative Learning scale and the Higher Order Thinking scale than with the Reflective Learning scale. These results further support the notion that teaching clarity is strongly related to important outcomes such as students' perceptions of gains and deep approaches to learning.

\section{Implications, Limitations, and Next Steps}

This study adds to research demonstrating that faculty who are perceived by students to be well prepared for class and design assignments that students consider clear and meaningful have consistently positive effects on student engagement and desired educational gains. The strength of the relationship between teaching clarity and the four NSSE benchmarks for first-year students suggests the need to emphasize the value of teaching clarity, particularly among faculty teaching first-year courses. In general, as all institutions are challenged to improve student learning and success, it is essential to focus on expanding students' exposure to practices that can make a significant difference in engagement and learning. Greater instructional clarity helps students understand expectations for the course and better identify with the instructor, and it can also promote the kinds of deep learning and educational gains desired for all students.

The findings from this study have specific implications for faculty development. Generally all of the clarity behaviors were frequently observed by most students, but it is worth noting deficiencies; for example, a quarter of first-year students rarely find that their instructors are making abstract ideas and theories understandable. These results suggest that faculty developers should expand their awareness of the value of teaching clarity for improving student engagement and the quality of learning. Results could also be promoted to foster a broader understanding among faculty, administrators, and students of the importance of teaching clarity and to expand investment in ensuring an emphasis of teaching clarity. For example, as part of their ongoing classroom evaluation, faculty could be encouraged to assess teaching clarity at the midpoint of a course for formative feedback. Development workshops could also be conducted in which faculty members share effective approaches to ensuring teaching clarity. In programs to prepare future faculty, emphases on teaching clarity can even be added to training in order to enrich the pedagogical techniques of tomorrow's professors. 
This study reflects an initial exploration of teaching clarity and student engagement, presenting a one-dimensional picture of teaching clarity. To provide a more comprehensive picture, the researchers have begun exploring faculty perceptions of the importance of teaching-clarity behaviors and the relationship between teaching clarity and other effective educational practices using data from the 2011 administration of the Faculty Survey of Student Engagement. Further examination of clarity perceptions and behaviors from both students and faculty will add valuable information about teaching practices in different fields.

As colleges and universities strive to improve undergraduate education and are challenged to enact a culture that assesses teaching quality based on the impact on student learning, it is important to emphasize the value of measurable practices like students' perceptions of teaching clarity. Past research has shown that teaching clarity is important for student learning, motivation, and achievement. The positive relationships between teaching clarity and learning and engagement shown here continue to support the position that teaching clarity is valuable and should be promoted as a goal in faculty development.

\section{REFERENCES}

Astin, A. W. (1993). What matters in college? Four critical years revisited. San Francisco, CA: Jossey-Bass.

Barr, R. B., \& Tagg, J. (1995). From teaching to learning: A new paradigm for undergraduate education. Change, 27(6), 13-25.

Chesebro, J. L., \& McCroskey, J. C. (2001). The relationship of teacher clarity and immediacy with student state receiver apprehension, affect and cognitive learning. Communication Education, 50(1), 59-68.

Cruickshank, D. R., \& Kennedy, J. J. (1986). Teaching clarity. Teaching and Teacher Education, 2(1), 43-47.

Feldman, K. A. (1989). The association between student ratings of specific instructional dimensions and student achievement: Refining and extending the synthesis of data from multisection validity studies. Research in Higher Education, 30, 583-645.

Ginsberg, S. M. (2007). Teacher transparency: What students can see from faculty communication. Journal of Cognitive Affective Learning, 4(1), 13-24.

Hativa, N. (1998). Lack of clarity in university teaching: A case study. Higher Education, 36(3), 353-381.

Hativa, N., Barak, R., \& Simhi, E. (2001). Exemplary university teachers: Knowledge and beliefs regarding effective teaching dimensions and strategies. Journal of Higher Education, 72(6), 699-729. 
Hayek, J., \& Kuh, G. (2004, March-April). Principles for assessing student engagement in the first year of college. Assessment Update, 16(2), 11-13.

Kuh, G. D. (2001a). Assessing what really matters to student learning: Inside the National Survey of Student Engagement. Change, 33(3), 10-17, 66.

Kuh, G. D. (2001b). The National Survey of Student Engagement: Conceptual framework and overview of psychometric properties. Bloomington: Indiana University, Center for Postsecondary Research.

Kuh, G. D. (2003). What we're learning about student engagement from NSSE. Change, 3.5(2), 24-32.

Kuh, G. D., Cruce, T., Shoup, R., Kinzie, J., \& Gonyea, R. M. (2008). Unmasking the effects of student engagement on college grades and persistence. Journal of Higher Education, 79, 540-563.

Kuh, G. D., Nelson Laird, T. F., \& Umbach, P. D. (2004). Aligning faculty and student behavior: Realizing the promise of expectations. Liberal Education, 90(4), 24-31.

Metcalf, K. K. (1992). The effects of a guided training experience on the instructional clarity of pre-service teachers. Teaching and Teacher Education, 8(3), 275-286.

Myers, S. A., \& Knox, R. L. (2001). The relationship between college student information-seeking behaviors and perceived instructor verbal behaviors. Communication Education, SO(4), 343-356.

Pace, C. R. (1980). Measuring the quality of student effort. Current Issues in Higher Education, 2, 10-16.

Pascarella, E. T. (2006). How college affects students: Ten directions for future research. Journal of College Student Development, 47, 508-520.

Pascarella, E., Edison, M., Nora, A., Hagedorn, L., \& Braxton, J. (1996). Effects of teacher organization/preparation and teacher skill/clarity on general cognitive skills in college. Journal of College Student Development, 37, 7-19.

Pascarella, E. T., Salisbury, M. H., \& Blaich, C. F. (2009, November). Exposure to effective instruction and college student persistence: $A$ multi-institutional replication and extension. Paper presented at the annual conference of the Association for Study of Higher Education, Vancouver, BC, Canada.

Pascarella, E. T., \& Terenzini, P. T. (1991). How college affects students: Findings and insights from twenty years of research. San Francisco, CA: Jossey-Bass.

Pascarella, E. T., \& Terenzini, P. T. (2005). How college affects students: A third decade of research (Vol. 2). San Francisco, CA: Jossey-Bass.

Sherman, T. M., Armistead, L. P., Fowler, F., Barksdale, M. A., \& Reif, G. (1987). The quest for excellence in university teaching. Journal of Higher Education, 58(1), 66-84. 
Umbach, P. D., \& Wawrzynski, M. R. (2005). Faculty do matter: The role of college faculty in student learning and engagement. Research in Higher Education, 46(2), 153-184.

Wabash National Study of Liberal Arts Education. (N.d.). High-impact practices and experiences from the Wabash National Study. Retrieved from http:/l www.liberalarts.wabash.edu/storage/High-Impact_Practices

_Summary06.01.09.pdf 